\title{
La frontera de
}

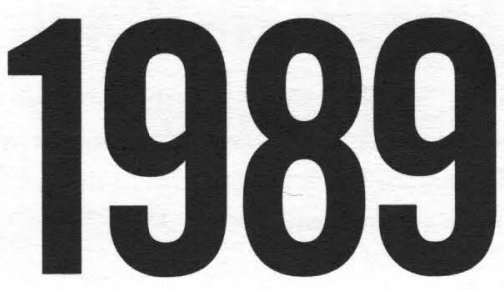

Francisco de Padea Vlluatoro Sánchel

Universidad de Cádiz

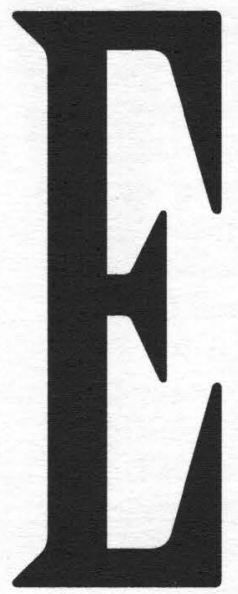

1 veinte aniversario de la caída del Muro de Berlín, la noche del 9 de noviembre de 1989, ha llevado a la realización de numerosos actos de conmemoración. Entre estos actos destaca, sin du$\mathrm{da}$, el IX Seminario Internacional «Nuestro Patrimonio Común», que se celebró entre el 9 y 11 de noviembre de 2009, dirigido por los profesores Marie-Claude Chaput y Julio Pérez Serrano, responsables, respectivamente, del Centre de Recherches Ibériques et Ibéro Américaines de la Universidad Paris Ouest Nanterre-La Défense y del Grupo de Estudios de Historia Actual de la Universidad de Cádiz.

A lo largo del Seminario, que tuvo lugar en la Facultad de Filosofía y Letras de la Universidad de Cádiz, se contó con la presencia de importantes investigadores procedentes de Universidades de reconocido prestigio internacional (Helsinki, Ankara, Paris I-Sorbonne,...), que a partir de sus ponencias han dado pie a una profunda reflexión y debate en torno a la significación histórica de la coyuntura de 1989 en las distintas problemáticas abordadas en las mesas que han compuesto el programa del Seminario.

Así, desde la perspectiva de la Historia actual, en el contexto geopolítico internacional, el fin de la Guerra Fría en 1989 supuso la extensión de la hegemonía militar de Estados Unidos y el modelo del capitalismo neoliberal por todo el planeta, abriendo importantes vías de reflexión en torno al papel de la Historia y la ideología, destacando análisis muy novedosos como los aportados por investigadores como Francis Démier y Marie-Claude Chaput. Paralelamente, el desmantelamiento del bloque soviético supuso en buena medida un importante descrédito de las ideas comunistas y de sus organizaciones. En este sentido, se incluyó en el programa del Seminario el debate en torno a la actualidad de las ideas comunistas y su reflejo en la sociedad en un momento de crisis del capitalismo global, siendo el germen de interesantes y novedosas aportaciones. Destaca, asimismo, para el caso español, la coincidencia de esta coyuntura histórica con la consolidación de un modelo de transición política al que se acercaron, desde diversas perspectivas, investigadores de varias Univer- sidades españolas ofreciendo parte de los resultados de un Proyecto coordinado del Plan Nacional de I+D centrado en el estudio de los movimientos sociales durante la Transición en la España meridional, dirigido por el profesor Pérez Serrano.

El desarrollo del programa contó igualmente con la celebración de dos sesiones de comunicaciones en las que participaron investigadores procedentes de varias Universidades españolas, como las de Salamanca, Cádiz, Alicante, etc. en las que se presentaron diversas investigaciones desarrolladas actualmente por distintos grupos de investigación de nuestro país en torno a problemáticas de la Historia Actual. Asimismo, la organización del Seminario incluyó la presentación de dos novedades editoriales relacionadas con la temática de las jornadas: de una parte, el número 6 de la $R e$ vista de Historia Actual, que dedica su dossier a «Partidos comunistas y pasado reciente», coordinado por la profesora Carmen González; y de otra, la de los dos primeros ejemplares de la nueva Colección de Historia Actual, editada por Editorial La Xara y la Asociación de Historia Actual, centrados, respectivamente, en el proceso de reunificación alemana y su repercusión en la seguridad europea, de Javier Lión Bustillo, y en el proceso de transición política en Centroamérica, de Jesús Fernández.

El programa académico del Seminario se completó con la conferencia de clausura, desarrollada por el cónsul general de la República Federal de Alemania en Sevilla, Dr. Berthold Johannes, que discurrió en torno a la visión alemana de un hecho tan importante para el pasado reciente de su país y la posterior construcción europea, aportando una perspectiva diferente que enriqueció la pluralidad de visiones y planteamientos presentes en el debate del Seminario.

A lo largo del transcurso del Seminario se desarrollaron interesantes debates entre los investigadores invitados en un ambiente relajado y cordial, abriendo varias vías novedosas de reflexión e investigación que fueron muy bien acogidas por el numeroso público asistente. En este sentido, el IX Seminario Internacional Nuestro Patrimonio Común mantiene la tradición de estos encuentros, organizados desde hace varios años por los profesores Julio Pérez Serrano y Marie-Claude Chaput, que se han coestituido en referente de la reflexión y el debate historiográfico crítico en torno a nuestro pasado más reciente. 


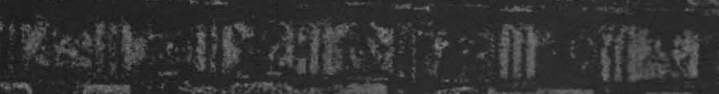

(1)

,

(1)

(1)

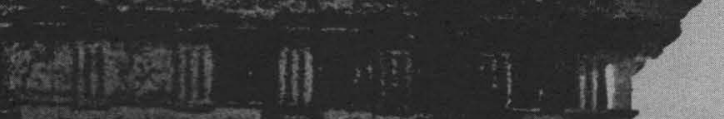

3.9.

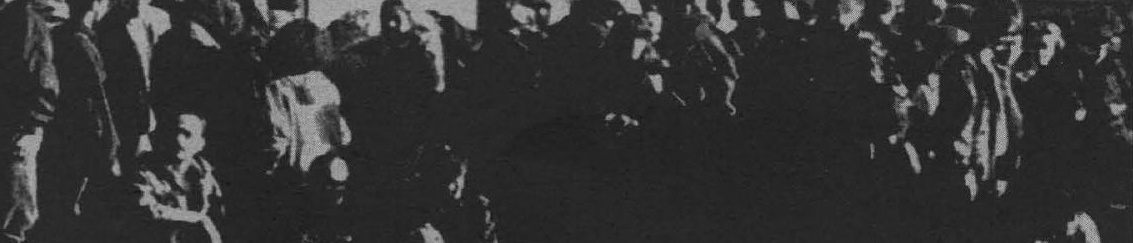

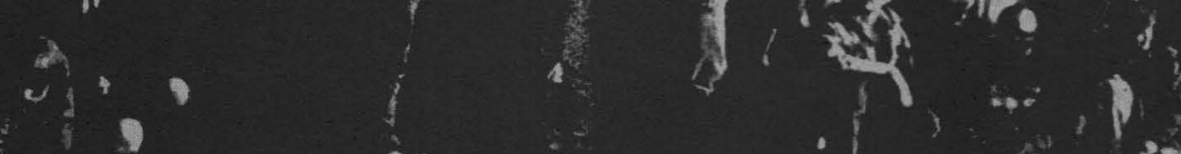

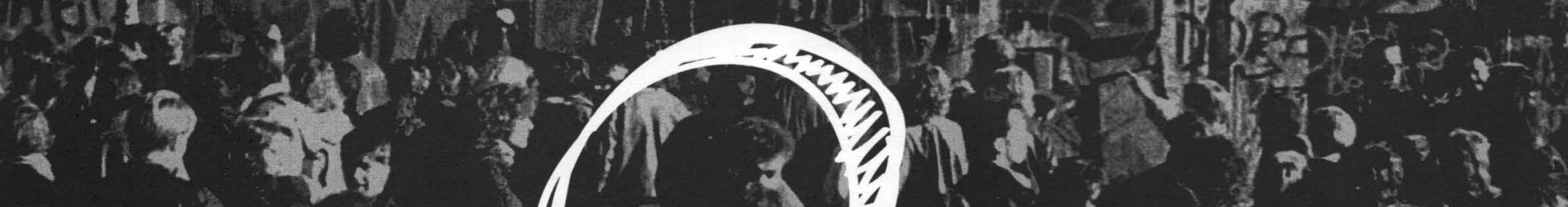

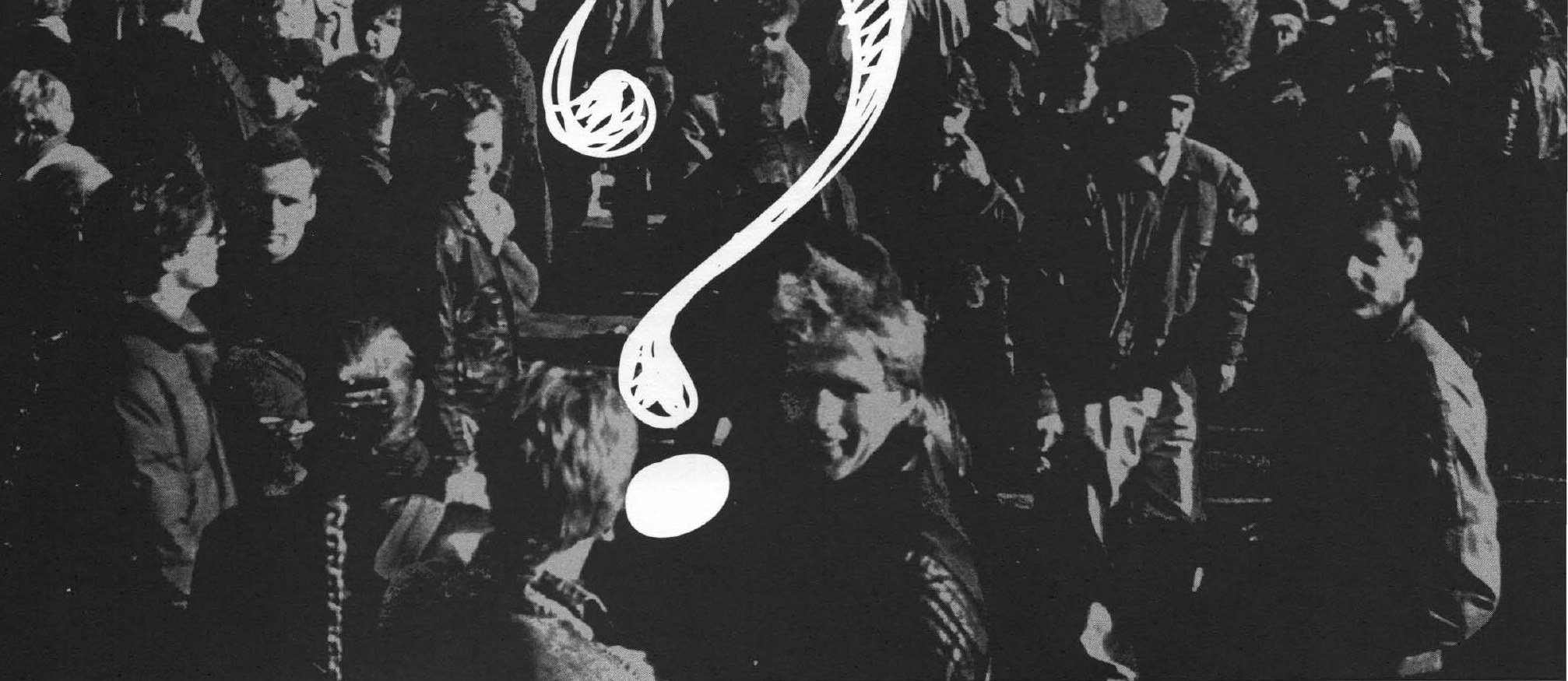

